\title{
Updated Topics in Healthcare Informatics
}

\author{
Hiroshi Takeda ${ }^{1,2,3}$ \\ ${ }^{1}$ Professsor Emeritus, Osaka Univeristy \\ 2-15 Yamada-Oka, Suita city, Osaka, 565-0871 Japan \\ ${ }^{2}$ Chief Research Fellow, Osaka Jikei Research Center of Healthcare Management, \\ 1-2-8 Miyahara, Yodogawa-ku, Osaka, 532-0003, Japan \\ ${ }^{3}$ Vice President, International Medical Informatics Association \\ h-takeda@jrhm.jikei.com
}

\begin{abstract}
This key note lecture introduces the role of IMIA, scope of healthcare informatics and some topics in healthcare informatics. Among updated topics, electronic patient record (EPR) and electronic health record (EHR) are featured. A new paradigm of clinical information systems, a document archiving and communication system (DACS) is also described and discussed.
\end{abstract}

Keywords: IMIA, Electronic Patient Record (EPR), electronic health record (EHR), document archiving and communication system (DACS).

\section{Overview of Healthcare Informatics}

To overview the scope of Healthcare Informatics, the Scientific Content Map (Table 1) that was developed in 2002 by IMIA's (then) Vice President for Working and Special Interest Groups, Dr. Nancy Lorenzi, is one of good references [1]. Current IMIA President Rheinhold Haux described ten major long-term aims and tasks for research in the field of medical informatics, including health informatics. These were the further development of methods and tools of information processing for: (1) diagnostics ('the visible body'); (2) therapy ('medical intervention with as little strain on the patient as possible'); (3) therapy simulation; (4) early-recognition and prevention; (5) compensating physical handicaps; (6) health consulting ('the informed patient'); (7) health reporting; (8) health care information systems; (9) medical documentation and (10) comprehensive documentation of medical knowledge and knowledge-based decision support [2]. In recent years, healthcare informatics would be gear up in accordance with advancement of internet and Web technology.

\section{The International Medical Informatics Association (IMIA)}

IMIA is an independent organization established under Swiss law in 1989. The organization was established in 1967 as Technical Committee 4 of the International Federation for Information Processing (IFIP). IMIA plays a major global role in the application of information science and technology in the fields of healthcare and research in medical, health and bio-informatics. In its function as a bridge 
Table 1. Scientific Content Map of the Healthcare Informatics (N. Lorennzi and IMIA, 2002)

\begin{tabular}{|c|c|c|c|c|c|}
\hline Applied Technology & $\begin{array}{l}\text { Information Technology } \\
\text { Infrastructure }\end{array}$ & $\begin{array}{l}\text { Data-Infrastructure } \\
\text { Related }\end{array}$ & Applications and Products & Human - Crganizational & Education and Knowledge \\
\hline Algorithms & \multicolumn{2}{|c|}{$\begin{array}{l}\text { Archival-repos itory systems for medical Class ification } \\
\text { records- EPR-CPR-EMR }\end{array}$} & Biostatistics & Assessment & Bibliographic \\
\hline Bioinformatics & Authentication & Coding sys tems & Clinical trials & Compliance & Cognitive leaming \\
\hline Bodean logic & Distributed systems & $\begin{array}{l}\text { Concept representation- } \\
\text { preservation }\end{array}$ & Decision s upport & Collaboration & $\begin{array}{l}\text { Computer-suppoted } \\
\text { training }\end{array}$ \\
\hline Cyptology & Health profess ional workstation & $\begin{array}{l}\text { Data acquis ition- data } \\
\text { capture }\end{array}$ & Diagnos is related & Communication & Consumer education \\
\hline Human gencme related & Interfaces & $\begin{array}{l}\text { Data analys is-extraction } \\
\text { tods }\end{array}$ & Disease mgt. & Economics of $I T$ & Continuing edwcation \\
\hline $\begin{array}{l}\text { Mathematical models in } \\
\text { medicine }\end{array}$ & Neural networks & Data pdicies & Event-baseds ystems & Diffusion of $\mathrm{IT}$ & H/Meducation \\
\hline \multirow[t]{14}{*}{ Pattern recognition } & Pen based & Data protection & Evidence based guidelines & Evaluation & $\begin{array}{l}\text { Information management- } \\
\text { dis semimation }\end{array}$ \\
\hline & Security & & Expert systems & Human Factors & Knowledge bases \\
\hline & Speech recognition & Database design & Health services research & $\begin{array}{l}\text { Legal issues, implementing } \\
\text { national laws }\end{array}$ & Knowledge management \\
\hline & Standards & Indexing & HIS management & Management & Learning models \\
\hline & Systems architecture & Syntax & Knowledge-bas ed systems & Managing Change & Online/dis tance education \\
\hline & \multirow{9}{*}{ User interfaces } & Nomenclatures & $\begin{array}{l}\text { Outcomes res earch and } \\
\text { meas urement }\end{array}$ & Privacy & \\
\hline & & & Qulity management & Project Management & \\
\hline & & Standards & & Security & \\
\hline & & Terminology-vocabulary & Patient identification & Strategic plans & \\
\hline & & & Patient monitoring & Unique identifiers & \\
\hline & & Thes aurus tools & Mnimum Data Sets & User-computer interface & \\
\hline & & & Supply chain & & \\
\hline & & & Telematics & & \\
\hline & & & Teleme dicine & & \\
\hline
\end{tabular}

organization, IMIA's goals are: 1) moving theory into practice by linking academic and research informaticians with care givers, consultants, vendors, and vendor-based researchers; 2) leading the international medical and health informatics communities throughout the 22nd century; 3 ) promoting the cross-fertilization of health informatics information and knowledge across professional and geographical boundaries; 4) serving as the catalyst for ubiquitous worldwide health information infrastructures for patient care and health research. The IMIA family includes a growing number of Working Groups (WG) and Special Interest Group (SIG), which consist of individuals who share common interests in a particular focal field. Current WGs and SIG are as follows: Biomedical Pattern Recognition, Consumer Health Informatics, Dental Informatics Health and Medical Informatics Education, Health Informatics for 
Development, Health Information Systems, Human Factors Engineering for Healthcare Informatics, Informatics in Genomic Medicine, Intelligent Data Analysis and Data Mining, Medical Concept Representation, Mental Health Informatics, Open Source Health Informatics, Organizational and Social Issues, Primary Health Care Informatics, Security in Health Information Systems, SIG NI Nursing Informatics, Smart Homes and Ambient Assisted Living, Standards in Health Care Informatics, Technology Assessment \& Quality Development in Health Informatics, Telematics in Health Care.

\section{Topics in Healthcare Informatics}

The pace of change in healthcare information environment has been particularly remarkable in the last decade, spurred on continuous needs to fulfill effectiveness and efficiency as well as equality in healthcare service. Among the advancements, some topics are described.

\subsection{Electronic Patient Record (EPR)}

In general, healthcare events contain data components pertaining to the three stages (observations, decisions and interventions) of a healthcare (clinical) process cycle. A patient record must describe those events as a function of time as official documents. In 1999, for example, the Japanese Ministry of Welfare authorized EPR in condition that integrity, preservability and readability are simultaneously assured in a clinical information system [3]. Since then, based on billing/accounting system, computerized physicians' order entry (CPOE), EPR systems have been deployed in healthcare facilities. However, there still exist paper-based clinical documents and sheets such as Informed-Consent sheet, referrals from other facilities and so on. As the patientspecific aggregation of digital-born and non-digital born data is so important to maintain healthcare management, a document archiving and communication system (DACS) has been proposed by the author as a new paradigm of healthcare information system. The first DACS was installed in the beginning of 2010 at Osaka University Hospital in Japan, where the total paperless system has been operated [4]. DACS also represent life-long readability and proof of electronic medical record as "Document-centric (electronic) Patient Record (DPR)".

\subsection{Electronic Health Record (EHR)}

EHR is electronic applications through which individuals can maintain and manage their health information in a secure and confidential environment. There may be two ways for EHR; Top-down and Bottom-up. The former is developed mainly in Nordic countries and United Kingdom. The latter is typically provided by Microsoft Vault and Google Health. In order to make EHRs interoperable and secure, standard bodies such as ISO TC215 should play an important role. It will be further considered for utilization of lifelong data for extracting "evidences" for research, education and management by means of integrated data-warehouse and data-mining methodology. 


\section{Conclusion}

Archiving and sharing healthcare information electronically can improve communications among caregivers and assist diagnosis, treatment and care in comprehensive healthcare delivery systems. Patients/citizens can have more control of their own healthcare. However, increasing access to data through EPR and EHR systems also brings new risks to the privacy and security of health records. Healthcare informaticians, information processing/communication professionals and stakeholders had better collaborate and cooperate to solve the practical problems.

\section{References}

1. http://www.imia.org/endorsed/2002_scientific_map.lasso

2. Haux, R.: Aims and tasks of medical informatics. Int. J. Med. Inf. 44(1), 9-20 (1997)

3. Takeda, H., Endoh, E.: Commentary on Health care in the information society. A prognosis for the year 2013. Int. J. Med. Inf. 66(1), 107-111 (2002)

4. Matsumura, Y., et al: A Scheme for Assuring Lifelong Readability in Computer Based Medical Records. In: Proc. MEDINFO 2010, Cape Town (2010) (in press) 